\title{
Desempenho de Frangos de Corte Alimentados com Rações Pré-iniciais Contendo Dife- rentes Níveis de Proteína Bruta e Energia Metabolizável
}

\author{
Patrícia Tironi Rocha1, José Henrique Stringhini 2,4 , Maria Auxiliadora Andrade ${ }^{3}$, Nadja Susana \\ Mogyca Leandro ${ }^{5}$, Michelle Lobo Andrade ${ }^{1}$, Marcos Barcellos Café 6
}

\begin{abstract}
RESUMO - Este experimento foi conduzido para avaliar o desempenho e a digestibilidade do nitrogênio e da matéria seca e medidas morfométricas para pintos de corte alimentados com rações contendo diferentes níveis de proteína e energia na fase pré-inicial ( 1 a 7 dias de idade). O delineamento experimental utilizado no experimento de desempenho foi o inteiramente casualizado em um fatorial $2 \times 3$ (energia: 2.850 e $3.000 \mathrm{kcal} / \mathrm{kg}$ e proteína: 20, 23 e 26\%) com quatro repetições de 14 aves cada. O ensaio de digestibilidade foi realizado durante a primeira semana, utilizando-se o método da coleta total de excretas, do $4^{\circ}$ ao $7^{\circ}$ dia de idade. Os resultados indicaram diferenças para o consumo de ração e conversão alimentar de 1 a 7 dias e diferenças no consumo de ração de 1 a 21 dias, mostrando que os níveis de 23 e $26 \%$ de proteína foram os que apresentaram as melhores respostas para a fase pré-inicial, nas condições deste experimento. Os níveis de energia metabolizável não influenciaram o desempenho nem os valores de digestibilidade da matéria seca e de nitrogênio.
\end{abstract}

Palavras-chave: desempenho, frango de corte, programa alimentar, ração pré-inicial

\section{Protein and Metabolizable Energy Levels in Pre-starter Rations (1-7 days) on Broiler Performance from 1 to 21 Days}

\begin{abstract}
This experiment was carried out in order to evaluate performance, nitrogen and dry matter balance and morfometrical measures of broilers raised with different levels of protein and energy on pre-starter phase ( 1 to 7 days of age). In a completely randomized design, 336 one-day old chicks were allotted in a completely randomized design in a factorial scheme $2 \times 3$ (metabolizable energy 2,850 and 3,000 kcal/kg and crude protein - 20, 23 and 26\%) with four replicates with 14 birds each. The digestibility trial occurred in the first week, and the total excreta collection method was used from 4 to 7 days of age. The results indicated that feed intake and feed conversion from 1 to 7 days, and feed intake from 1 to 21 days, showing that the $23 \%$ and $26 \%$ CP gave the best results for pre-starter phase in this experiment. The metabolizable energy levels did not affect the performance neither nutritional balances of dry matter and nitrogen.
\end{abstract}

Key Words: broiler, feeding program, pre-starter ration, performance

\section{Introdução}

Pesquisas sobre a nutrição de frangos de corte durante a primeira semana de vida têm sido intensificadas e difundidas devido à alta correlação entre o peso dos pintos no sétimo dia de vida e o seu respectivo peso ao abate. Esta fase representa cerca de $20 \%$ do período de vida da ave, quando ocorre a maior taxa de crescimento relativo do pintinho (Dibner, 1996; Gonzáles \& Saldanha, 2001).

As principais razões que justificam uma dieta específica na primeira semana de vida são a anatomia e a fisiologia diferenciada do aparelho digestivo, as necessidades nutricionais limitantes pelas dificuldades em digerir e absorver certos nutrientes, o rápido desenvolvimento potencial nos primeiros dias de vida e a grande dificuldade de garantir a sobrevivência em ambientes frios (Moran Jr.; 1985, Penz \& Vieira, 1998; Croom et al., 1999).

Lima (1996), ao apresentar os níveis nutricionais normalmente empregados por empresas de integração e pequenos produtores de frangos de corte, mostrou que, para a fase pré-inicial (1 a 7 dias), os níveis de proteína bruta empregados variam entre 21 e $22 \%$ e

\footnotetext{
${ }_{1}^{1}$ Médica Veterinária e aluna de Mestrado em Medicina Veterinária da Escola de Veterinária da UFG.

2 Professor do Departamento de Produção Animal da Escola de Veterinária da UFG - Caixa Postal 131, 74001-970, Goiânia - GO. E. mail: henrique@vet.ufg.br

${ }^{3}$ Professora do Departamento de Medicina Veterinária da Escola de Veterinária da UFG - Caixa Postal 131, 74001-970, Goiânia - GO E.mail:maa@vet.ufg.br

${ }^{4}$ Bolsista do CNPq.

5 Professor do Departamento de Produção Animal da Escola de Veterinária da UFG - Caixa Postal 131, 74001-970, Goiânia - GO. E. mail: mogyca@vet.ufg.br

${ }^{6}$ Professor do Departamento de Produção Animal da Escola de Veterinária da UFG - Caixa Postal 131, 74001-970, Goiânia - GO. E. mail: mcafe@vet.ufg.br
} 
os de energia metabolizável oscilam entre 2.920 e $2.950 \mathrm{kcal} / \mathrm{kg}$ e para a fase inicial variam de $20 \%$ a $21 \%$ e 2.950 a $3.050 \mathrm{kcal} / \mathrm{kg}$, respectivamente.

$\mathrm{O}$ crescimento das vilosidades intestinais na ave jovem e o aumento de células nas criptas são estimulados pela presença do alimento. Em machos White Leghorn avaliados durante a primeira semana, a alimentação ad libitum iniciada o mais rapidamente possível estimulou o crescimento intestinal e consequentemente o aumento da superfície absortiva, enquanto o jejum resultou em atraso no desenvolvimento intestinal (Baranyiová \& Holman, 1976; Moran Jr., 1985).

Uni et al. (1995a), avaliando o desenvolvimento do intestino delgado nas linhagens Arbor Acres (pesada) e Lohmann (leve) antes e depois do nascimento, observaram uma maior altura e perímetro das vilosidades intestinais, bem como maior profundidade das criptas na linhagem pesada, e observaram também que a concentração de DNA no tecido duodenal aumentou com a idade. Em perus, Uni et al. (1995b) encontraram menor tamanho e área dos vilos e também menor atividade enzimática em comparação com pintos de corte.

As limitações na atividade enzimática e digestiva estão presentes na primeira semana de vida dos pintos. Noy \& Sklan(1995), trabalhando com frangos Arbor Acres aos quatro dias de idade, mostraram que a digestão protéica no intestino delgado aumentou de $78 \%$, aos quatro dias de idade, para $92 \%$ aos 21 dias, enquanto, para ácidos graxos e amido, as taxas aumentaram de 82 para $89 \%$.

Nitsan et al. (1991) também observaram um aumento das enzimas digestivas relacionadas com a idade das aves. Os valores máximos da amilase e lipase no pâncreas foram observados aos 8 dias de idade, e no intestino delgado os valores máximos foram obtidos aos 4 dias de idade para a lipase e aos 17 dias de idade para a amilase.

Mahagna \& Nir (1996), avaliando o desenvolvimento da atividade de enzimas envolvidas com a digestão de carboidratos, concluíram que a atividade das dissacaridases (maltase e sacarase), até os sete dias de idade, é maior nas aves tipo carne do que nas de postura e, após essa idade, essa atividade é maior nas aves de postura. Lu \& Shen (1998) verificaram, em frangos de corte Arbor Acres, que o pico de atividade da tripsina e da quimiotripsina ocorreram aos 7 e 21 dias de idade, e para pepsina, aos 14 dias de idade.

Noy \& Sklan (1995) citam que a secreção de componentes biliares, incluindo sais biliares e ácidos graxos, aumentou de oito para dez vezes entre o $4^{\circ} \mathrm{e}$ $21^{\circ}$ dia após a eclosão.

Freitas et al. (1999), trabalhando com avaliações da digestibilidade aparente de extrato etéreo e de proteína bruta para frangos de corte alimentados com rações com ou sem inclusão de óleo de soja, encontraram alta digestibilidade na primeira semana para o extrato etéreo, acompanhada de queda na segunda semana e um novo aumento na terceira semana. A digestibilidade da proteína bruta esteve em torno de $70 \%$ durante a primeira semana, caiu a menos de $60 \%$ na segunda semana e voltou a subir aos 21 dias de idade.

Pintos de corte deutectomizados apresentaram uma taxa inicial de crescimento intestinal baixa, que é compensada por volta do $6^{\circ}$ ao $8^{\circ}$ dia de vida no duodeno. Esses achados sugerem que a provisão de nutrientes da gema é mais importante para o desenvolvimento da mucosa intestinal (Uni et al., 1998).

Nitsan et al. (1991) observaram que o peso do saco vitelino decresceu rapidamente de 4,6 gramas à eclosão para 0,5 gramas aos quatro dias de idade, e após esse período o seu peso passou a valores negligenciáveis. À eclosão, o saco vitelino continha 2.260 miligramas de matéria seca (940 miligramas de gordura e 1.320 miligramas de proteína) e o saco vitelino contribuiu com, aproximadamente, $50 \%$ e $40 \%$ do total de suprimento de energia e proteína respectivamente (do alimento e do saco vitelino) no primeiro dia após o nascimento, e somente $2 \%$ e $6 \%$ para energia e proteína, no quarto dia de idade, respectivamente.

Diante do exposto, o presente trabalho teve por objetivos: avaliar o desempenho produtivo de frangos de corte no período de 1 a 21 dias de idade, recebendo rações pré-iniciais (1 a 7 dias) com diferentes níveis de proteína bruta e energia metabolizável; verificar o coeficiente de digestibilidade do nitrogênio e da matéria seca para as mesmas rações; e mensurar as relações corporais (o peso dos órgãos em relação ao peso corporal) e o peso dos órgãos e o comprimento dos intestinos aos 7 e aos 21 dias de idade.

\section{Material e Métodos}

O experimento foi conduzido no aviário experimental do Departamento de Produção Animal da Escola de Veterinária da Universidade Federal de Goiás, em Goiânia - GO, nos meses de julho e agosto de 1998.

Foram utilizados 336 pintos de um dia, machos da linhagem Hubbard, criados em baterias aquecidas

R. Bras. Zootec., v.32, n.1, p.162-170, 2003 
com cinco andares e divisões de $0,33 \times 0,50 \mathrm{~m}$ até 21 dias, depois transferidos para boxes de $1,0 \times 1,0 \mathrm{~m}$ no $22^{\circ}$ dia de vida. As baterias de aço galvanizado apresentavam cinco andares com divisões de $0,33 \mathrm{x}$ $0,50 \mathrm{~m}$ e eram equipadas com comedouros e bebedouros tipo lineares e bandejas metálicas colocadas sob as gaiolas para retirada das excretas. Uma lâmpada incandescente de $60 \mathrm{~W}$ para cada andar foi utilizada até aproximadamente 12 dias de idade para o aquecimento das aves. O galpão onde se encontravam as baterias era provido de cortinas laterais, que eram manejadas de acordo com a temperatura e o comportamento das aves. Ração e água foram fornecidas à vontade.

As aves foram distribuídas em um delineamento experimental inteiramente casualizado, num esquema fatorial $2 \times 3$ (energia $x$ proteína) com quatro repetições contendo 14 aves cada.

As rações (Tabela 1), elaboradas à base de milho e farelo de soja, eram de baixa $(2.850 \mathrm{kcal} / \mathrm{kg})$ e de alta $(3.000 \mathrm{kcal} / \mathrm{kg})$ energia metabolizável e níveis de proteína bruta de 20,23 e $26 \%$. As exigências nutricionais e a composição dos alimentos utilizados seguiram as recomendações de Rostagno et al. (1994) para a fase inicial, exceto para os níveis de proteína bruta e de energia metabolizável testados. As rações experimentais foram fornecidas às aves durante a primeira semana de vida e, após este período, todos os tratamentos passaram a receber uma ração única para fase inicial, com $21 \%$ de PB e $2.950 \mathrm{kcal} / \mathrm{kg}$ de $\mathrm{EM}$, até os 21 dias.

As aves e as rações foram semanalmente pesadas e posteriormente calculados o consumo de ração, o ganho de peso e a conversão alimentar. Após o experimento para testar o desempenho, realizou-se um ensaio de metabolismo durante a primeira semana, utilizando-se o método da coleta total de excretas, do $4^{\circ}$ ao $7^{\circ}$ dia de idade. As excretas foram colhidas duas vezes ao dia, acondicionadas em sacos plásticos identificados com o tratamento e repetição e congeladas $\left(-18^{\circ} \mathrm{C}\right)$ para posteriores análises.

As análises de ração e excretas foram realizadas no Laboratório de Nutrição Animal do Departamento de Produção Animal da Escola de Veterinária da

Tabela 1 - Composição das dietas nas fases pré-inicial e inicial

Table 1 - Composition of the pre-starter and starter diets

\begin{tabular}{|c|c|c|c|c|c|c|c|}
\hline \multirow[t]{2}{*}{$\begin{array}{l}\text { Ingredientes } \\
\text { Ingredients }\end{array}$} & \multicolumn{6}{|c|}{$\begin{array}{l}\text { Rações pré-iniciais } \\
\text { Pre-starter rations }\end{array}$} & \multirow[t]{2}{*}{$\begin{array}{l}\text { Inicial } \\
\text { Starter }\end{array}$} \\
\hline & A & $\mathrm{B}$ & $\mathrm{C}$ & $\mathrm{D}$ & $\mathrm{E}$ & $\mathrm{F}$ & \\
\hline Milho (Corn) & 61,42 & 55,88 & 45,75 & 62,17 & 52,45 & 42,15 & 61,10 \\
\hline Farelo de soja (Soybean meal) & 33,60 & 39,98 & 48,41 & 32,24 & 40,64 & 49,08 & 35,00 \\
\hline Óleo de soja (Soybean oil) & - & 0,27 & 1,98 & 1,56 & 3,21 & 4,91 & - \\
\hline Fosfato bicálcico (Dicalcium phosphate) & 2,29 & 2,22 & 2,19 & 2,27 & 2,24 & 2,20 & 2,00 \\
\hline Calcário calcítico (Limestone) & 0,94 & 0,92 & 0,87 & 0,96 & 0,91 & 0,86 & 1,10 \\
\hline Sal comum (Salt) & 0,35 & 0,35 & 0,35 & 0,35 & 0,35 & 0,35 & 0,30 \\
\hline Supl. mineral-vitamínico (Mineral vitamin supplement) ${ }^{1,2}$ & 0,40 & 0,40 & 0,40 & 0,40 & 0,40 & 0,40 & 0,40 \\
\hline Inerte (Inert) & 1,00 & 0,05 & 0,05 & 0,05 & 0,05 & 0,05 & - \\
\hline Total & 100,0 & 100,0 & 100,0 & 100,0 & 100,0 & 100,0 & 100,0 \\
\hline \multicolumn{8}{|l|}{ Níveis nutricionais (Nutritional levels) } \\
\hline Proteína bruta (\%) (Crude protein \%) & 20,0 & 23,0 & 26,0 & 20,0 & 23,0 & 26,0 & 21,2 \\
\hline Energia metabolizável ( $\mathrm{kcal} / \mathrm{kg}$ ) (Metabolizable energy $k c a l / k g)$ & 2.850 & 2.850 & 2.850 & 3.000 & 3.000 & 3.000 & 2.888 \\
\hline Cálcio (\%)(Calcium\%) & 1,031 & 1,023 & 1,025 & 1,024 & 1,027 & 1,025 & 1,019 \\
\hline $\mathrm{P}$ disp. (\%) (Available phosphorus \%) & 0,543 & 0,534 & 0,534 & 0,535 & 0,536 & 0,534 & 0,487 \\
\hline Sódio (Sodium \%) & 0,184 & 0,187 & 0,193 & 0,182 & 0,188 & 0,170 & 0,163 \\
\hline Met + Cis $(\%)(M e t+C y s \%)$ & 0,729 & 0,795 & 0,874 & 0,723 & 0,792 & 0,870 & 0,746 \\
\hline Lisina $(\%)($ Lysine \%) & 1,106 & 1,276 & 1,495 & 1,068 & 1,287 & 1,506 & 1,145 \\
\hline
\end{tabular}

1 Para a ração inicial: Cloreto de colina $220 \mathrm{~g} /$ tonelada + Suplemento vitamínico - fase inicial, níveis de garantia por quilograma de produto: 8.000.000 UI Vitamina A, 2.000.000 UI Vitamina D3, 15.000 UI Vitamina E, $1.800 \mathrm{mg}$ Vitamina K, $1.800 \mathrm{mg}$ Vitamina B1, $6.000 \mathrm{mg}$ Vitamina B2, $2.800 \mathrm{mg}$ Vitamina B6, $12.000 \mathrm{mcg}$ Vitamina B12, $40.000 \mathrm{mg}$, Niacina, $1.000 \mathrm{mg}$ Ácido fólico, $15.000 \mathrm{mg}$ Ácido Pantotênico, $60 \mathrm{mg}$ de Biotina, 300mg Selênio, 30g Antioxidante, metionina —- mg

2 Para todas as rações: Suplemento Mineral para aves, níveis de garantia por quilograma de produto: 150.000 mg Manganês, 100.000 $\mathrm{mg}$ Zinco, $100.000 \mathrm{mg}$ Ferro, $16.000 \mathrm{mg}$ Cobre, $1.500 \mathrm{mg}$ lodo.

1 To starter ration: Choline chloride $220 \mathrm{~g} / \mathrm{t}+$ supplement, levels per kilogram: 8.000.000UI Vitamin A, 2.000.000 UI Vitamin D3, 15.000 UI Vitamin E, 1.800 $\mathrm{mg}$ Vitamin K, $1.800 \mathrm{mg}$ Vitamin B1, 6.000mg Vitamin B2, 2.800 mg Vitamin B6, $12.000 \mathrm{mcg}$ Vitamin B12, $40.000 \mathrm{mg}$, Niacin, $1.000 \mathrm{mg}$ Folic acid, $15.000 \mathrm{mg}$ Pantotenic acid, $60 \mathrm{mg}$ de Biotin, $300 \mathrm{mg}$ Selenium, $30 \mathrm{~g}$ Antioxidant, methionine, _- $\mathrm{mg}$

${ }^{2}$ To all rations: levels per kilogram: $150.000 \mathrm{mg}$ Manganese, $100.000 \mathrm{mg}$ Zinc, $100.000 \mathrm{mg}$ Iron, $16.000 \mathrm{mg}$ Copper, $1.500 \mathrm{mg}$ lodine.

\section{R. Bras. Zootec., v.32, n.1, p.162-170, 2003}


UFG, de acordo com a metodologia proposta por Silva (1990), para matéria seca a $55^{\circ} \mathrm{C}$ das excretas, matéria seca a $105^{\circ} \mathrm{C}$ e nitrogênio total das rações experimentais, e das excretas pelo método de microKjeldahl.

Aos 7 e 21 dias de idade, 24 aves (quatro aves por tratamento, uma de cada repetição) foram transportadas ao Laboratório de Doenças de Aves do Departamento de Medicina Veterinária da Escola de Veterinária da UFG e submetidas a um período de jejum de aproximadamente cinco horas. Estas aves foram sacrificadas por deslocamento cervical e posteriormente pesadas. Foram anotados os pesos individuais do fígado, do coração, dos intestinos, da moela. Foram também mensurados os comprimentos dos intestinos. Posteriormente foram feitas relações em percentual de cada órgão com o peso corporal.

Os dados foram analisados utilizando-se o programa Estat (Sistema de Análises Estatísticas), desenvolvido pelo Departamento de Ciências Exatas da Unesp/ Campus de Jaboticabal, e as médias foram comparadas pelo teste de Tukey a $5 \%$ de probabilidade.

\section{Resultados e Discussão}

Para os dados de desempenho obtidos, não foi observada interação significativa $(\mathrm{P}>0,05)$. O desempenho de 1 a 7 dias foi afetado pelos níveis de proteína (Tabela 2). O consumo de ração reduziu com o aumento de proteína na ração, o que resultou em uma melhor conversão alimentar. Stringhini (1998), trabalhando com níveis de 20, 22, 24 e 26\% de PB na fase inicial, observou, para o período de 1 a 7 dias, maior ganho de peso para a ração com $22 \% \mathrm{~PB}$, maior consumo e pior conversão alimentar para $20 \%$ de PB, o que concorda parcialmente com os resultados deste trabalho.

Os níveis de energia metabolizável utilizados nas rações experimentais $(2.850$ e $3.000 \mathrm{kcal} / \mathrm{kg})$ não determinaram diferenças estatísticas nos parâmetros de desempenho de 1 a 7 dias (Tabela 2). Maiorka et al. (1997), avaliando rações contendo 2.900, $3.000 \mathrm{e}$ $3.100 \mathrm{kcal} \mathrm{EM} / \mathrm{kg}$ de 1 a 21 dias, não encontraram diferença para o desempenho de 1 a 7 dias. Dados semelhantes foram observados por Nobre et al. (1998), que avaliaram o desempenho de frangos de corte recebendo rações com dois níveis de energia metabolizável $(2.850$ e $3.100 \mathrm{kcal} / \mathrm{kg})$ e dois níveis de taurina (0 e $0,1 \%)$, no período de 1 a 21 dias. $O$ consumo de ração da $2^{\mathrm{a}}$ semana (Tabela 3 ) foi diferente $(\mathrm{P}<0,05)$ para os níveis de energia das rações pré-iniciais, com maior valor para $3.000 \mathrm{kcal} / \mathrm{kg}$.

Maiorka et al. (1997) encontraram resultados contrários aos observados no presente experimento, com um consumo de ração em relação inversa aos níveis crescentes de energia metabolizável da ração. Os autores verificaram ainda que, no período de 7 a 14 dias, os melhores ganhos de peso e conversão alimentar foram observados nas dietas com níveis mais altos de energia ( $3.100 \mathrm{kcal} / \mathrm{kg})$.

Nobre et al. (1998), em experimento com níveis de energia metabolizável e taurina, não encontraram diferença significativa para conversão alimentar e ganho de peso no período de 8 a 14 dias, mas os melhores resultados de ganho de peso foram obtidos com $3.100 \mathrm{kcal} / \mathrm{kg}$.

Nenhuma diferença estatística significativa foi observada no desempenho das aves no período de 14 a 21 dias (Tabela 4).

Maiorka et al. (1997) encontraram diferença esta-

Tabela 2 - Desempenho de frangos de corte de 1 a 7 dias recebendo as rações experimentais ${ }^{1}$ Table 2 - Broiler performance from 1 to 7 days fed experimental rations ${ }^{1}$

\begin{tabular}{lcccc}
\hline & & $\begin{array}{c}\text { Ganho de peso }(\mathrm{g}) \\
\text { Weight gain }(\mathrm{g})\end{array}$ & $\begin{array}{c}\text { Consumo de ração (g) } \\
\text { Feed intake }(\mathrm{g})\end{array}$ & $\begin{array}{c}\text { Conversão alimentar } \\
\text { Feed-to-gain ratio }\end{array}$ \\
\hline $\mathrm{EM}(\mathrm{kcal} / \mathrm{kg})$ & 2.850 & 93,0 & 113,2 & 1,218 \\
$M E(\mathrm{kcal} / \mathrm{kg})$ & 3.000 & 94,4 & 115,9 & 1,228 \\
Proteína (\%) & 20 & $96,9 \mathrm{a}$ & $122,3 \mathrm{a}$ & $1,263 \mathrm{a}$ \\
Protein (\%) & 23 & $89,3 \mathrm{~b}$ & $110,4 \mathrm{~b}$ & $1,237 \mathrm{ab}$ \\
$\mathrm{CV}$ & 26 & $95,0 \mathrm{ab}$ & $111,0 \mathrm{~b}$ & $1,170 \mathrm{~b}$ \\
\hline
\end{tabular}

\footnotetext{
${ }^{1}$ Letras diferentes nas colunas indicam diferença estatística significativa (Tukey, $5 \%$ ).

${ }^{1}$ Minor letters in the rows indicates statistical difference (Tukey, $5 \%$ ).

${ }^{2} \mathrm{CV}=$ coeficiente de variação.

${ }^{2} \mathrm{CV}=$ coefficient of variation.
}

R. Bras. Zootec., v.32, n.1, p.162-170, 2003 
Tabela 3 - Desempenho de frangos de corte de 7 a 14 dias recebendo as rações experimentais ${ }^{1}$ Table 3 - Broiler performance from 7 to 14 days fed experimental rations ${ }^{1}$

\begin{tabular}{lcccc}
\hline & & $\begin{array}{c}\text { Ganho de peso }(\mathrm{g}) \\
\text { Weight gain }(\mathrm{g})\end{array}$ & $\begin{array}{c}\text { Consumo de ração }(\mathrm{g}) \\
\text { Feed intake }(\mathrm{g})\end{array}$ & $\begin{array}{c}\text { Conversão alimentar } \\
\text { Feed-to-gain ratio }\end{array}$ \\
\hline $\mathrm{EM}(\mathrm{kcal} / \mathrm{kg})$ & 2.850 & 206,7 & $306,1 \mathrm{~b}$ & 1,485 \\
$M E(\mathrm{kcal} / \mathrm{kg})$ & 3.000 & 210,9 & $315,0 \mathrm{a}$ & 1,500 \\
Proteína (\%) & 20 & 213,0 & 314,5 & 1,479 \\
Protein (\%) & 23 & 198,9 & 304,1 & 1,535 \\
$\mathrm{CV}^{2}(\%)$ & 26 & 214,4 & 313,1 & 1,463 \\
\hline
\end{tabular}

${ }^{1}$ Letras diferentes nas colunas indicam diferença estatística significativa (Tukey, $5 \%$ ).

1 Minor letters in the rows indicates statistical difference (Tukey, 5\%).

${ }^{2} \mathrm{CV}=$ coeficiente de variação.

$2 \mathrm{CV}=$ coefficient of variation.

Tabela 4 - Desempenho de frangos de corte de 14 a 21 dias recebendo as rações experimentais ${ }^{1}$ Table 4 - Broiler performance from 14 to 21 days fed experimental rations ${ }^{1}$

\begin{tabular}{lcccc}
\hline & & $\begin{array}{c}\text { Ganho de peso (g) } \\
\text { Weight gain (g) }\end{array}$ & $\begin{array}{c}\text { Consumo de ração (g) } \\
\text { Feed intake (g) }\end{array}$ & $\begin{array}{c}\text { Conversão alimentar } \\
\text { Feed-to-gain ratio }\end{array}$ \\
\hline EM (kcal/kg) & 2.850 & 306,0 & 507,8 & 1,668 \\
$M E(k c a l / g)$ & 3.000 & 304,8 & 502,7 & 1,652 \\
Proteína (\%) & 20 & 311,7 & 507,2 & 1,629 \\
Protein (\%) & 23 & 305,2 & 502,8 & 1,653 \\
CV $^{1}(\%)$ & 26 & 299,3 & 505,7 & 1,698 \\
\hline
\end{tabular}

${ }_{1}^{1} \mathrm{CV}=$ coeficiente de variação.

${ }^{1} \mathrm{CV}=$ coefficient of variation.

tística significativa para consumo de ração, ganho de peso e conversão alimentar no período de 14 a 21 dias, com um consumo de ração em relação inversa aos níveis crescentes de energia metabolizável na ração, o que afetou o ganho de peso e a conversão alimentar das aves.

Nobre et al. (1998) também encontraram diferença estatística significativa no período de 15 a 21 dias para ganho de peso e conversão alimentar, e a dieta com $3.100 \mathrm{kcal} / \mathrm{kg}$ obteve melhor ganho de peso e conversão alimentar.

Os níveis de proteína influenciaram significativamente apenas o consumo de ração no período de 1 a 21 dias (Tabela 5), e os níveis de 20\% determinaram valor superior aos níveis de $23 \%$.

Nascimento et al. (1998), em experimento avaliando níveis de energia e relação energia: proteína na fase inicial (1 a 21 dias) de frangos de corte, encontraram diferença estatística significativa para o consumo de ração para a relação energia: proteína de 136,9 (rações com 2.850:20,82; 3.000:21,92; $3.150: 23,01)$. Os autores não encontraram diferença no consumo de ração relacionada aos níveis de energia metabolizável das rações.

Stringhini (1998), em experimento com frangos de corte testando níveis de proteína, aminoácidos e densidade populacional, sugeriu serem os níveis de 23 e $21 \%$ os mais indicados, respectivamente, para as fases pré-inicial e inicial.

Houve diferença estatística significativa $(\mathrm{P}<0,05)$ para a digestibilidade da matéria seca em relação aos níveis de proteína das rações (Tabela 6), e as rações com $20 \%$ de PB apresentaram maior retenção de matéria seca, seguidas das rações com 23 e $26 \%$ de PB. Não houve diferença estatística significativa para a digestibilidade de nitrogênio nas rações testadas (Tabela 6). De acordo com Noy \& Sklan (1995), neste período a proteólise não é suficiente o bastante para efetuar a hidrólise de proteínas endógenas e exógenas, e pode-se supor que os resultados encontrados relacionam-se a uma menor digestibilidade da proteína, que pode ter interferido na digestibilidade dos nutrientes de forma geral. 
Tabela 5 - Desempenho de frangos de corte de 1 a 21 dias recebendo as rações experimentais ${ }^{1}$ Table 5 - Broiler performance from 1 to 21 days fed experimental rations ${ }^{1}$

\begin{tabular}{lcccc}
\hline & Ganho de peso $(\mathrm{g})$ & $\begin{array}{c}\text { Consumo de ração (g) } \\
\text { Feight gain }(\mathrm{g})\end{array}$ & $\begin{array}{c}\text { Conversão alimentar } \\
\text { Feed-to-gain ratio }\end{array}$ \\
\hline $\mathrm{EM}(\mathrm{kcal} / \mathrm{kg})$ & 2.850 & 603,0 & 927,2 & 1,540 \\
$M E(\mathrm{kcal} / \mathrm{kg})$ & 3.000 & 610,2 & 933,7 & 1,533 \\
Proteína (\%) & 20 & 617,5 & $944,1 \mathrm{a}$ & 1,530 \\
Protein (\%) & 23 & 593,5 & $917,4 \mathrm{~b}$ & 1,550 \\
& 26 & 608,7 & $929,8 \mathrm{ab}$ & 1,530 \\
$\mathrm{CV}(\%)$ & & 4,45 & 2,07 & 4,00 \\
\hline
\end{tabular}

${ }^{1}$ Letras diferentes nas colunas indicam diferença estatística significativa (Tukey, $5 \%$ ).

${ }^{1}$ Minor letters in the rows indicates statistical difference (Tukey, 5\%).

${ }^{2} \mathrm{CV}=$ coeficiente de variação.

${ }^{2} \mathrm{CV}=$ coefficient of variation

Tabela 6 - Digestibilidade da matéria seca e nitrogênio das rações experimentais fornecidas no período de 1 a 7 dias de idade de frangos de corte ${ }^{1}$

Table 6 - Dry matter and nitrogen digestibility from 1 to 7 days for broilers fed experimental rations ${ }^{1}$

\begin{tabular}{lccc}
\hline & & \multicolumn{2}{c}{$\begin{array}{c}\text { Digestibilidade (\%) } \\
\text { Digestibility (\%) }\end{array}$} \\
\cline { 3 - 4 } & & $\begin{array}{c}\text { Matéria seca } \\
\text { Dry matter }\end{array}$ & $\begin{array}{c}\text { Nitrogênio } \\
\text { Nitrogen }\end{array}$ \\
\hline $\mathrm{EM}(\mathrm{kcal} / \mathrm{kg})$ & 2.850 & 67,96 & 53,68 \\
ME $(\mathrm{kcal} / \mathrm{kg})$ & 3.000 & 68,38 & 54,76 \\
Proteína (\%) & 20 & $70,83 \mathrm{a}$ & 54,93 \\
Protein (\%) & & & \\
& 23 & $68,58 \mathrm{~b}$ & 53,49 \\
$\mathrm{CV}^{2}(\%)$ & 26 & $65,11 \mathrm{c}$ & 54,24 \\
\hline
\end{tabular}

1 Letras diferentes nas colunas indicam diferença estatística significativa (Tukey, 5\%).

${ }^{1}$ Minor letters in the rows indicates statistical difference (Tukey, 5\%).

$2 \mathrm{CV}=$ coeficiente de variação.

$2 \mathrm{CV}=$ coefficient of variation
Com relação ao percentual de peso dos intestinos aos 7 dias de idade, os dois níveis mais altos de proteína bruta ( 23 e $26 \%$ ) determinaram pesos maiores do que os tratamentos com $20 \%$ de proteína (Tabela 7). Não houve diferença estatística para os demais órgãos mensurados, mas convêm observar o maior percentual de peso da moela nos tratamentos com $23 \%$ de proteína bruta.

Houve diferença estatística significativa na interação entre os níveis de energia (2.850 e 3.000 $\mathrm{kcal} / \mathrm{kg}$ ) dentro do nível de $23 \%$ de $\mathrm{PB}$, em que o menor nível de energia da dieta $(2.850 \mathrm{kcal} / \mathrm{kg})$ mostrou um percentual de peso dos intestinos $(5,99 \%)$ maior do que os níveis de $3.000 \mathrm{kcal} / \mathrm{kg}$, em que os pesos relativos foram de $5,05 \%$.

A interação entre os níveis de proteína $(20,23$ e 
Tabela 7 - Comprimento do intestino, pesos relativos (peso dos órgãos em relação ao peso corporal) dos intestinos, do fígado, da moela e do coração de frangos de corte aos 7 dias de idade, recebendo as rações experimentais ${ }^{1}$

Table 7 - Intestine height, relative weight (organ weight related to body weight) for intestines, liver, gizzard and heart from broilers at 7 days fed experimental rations ${ }^{1}$

\begin{tabular}{|c|c|c|c|}
\hline & & \multicolumn{2}{|c|}{$\begin{array}{l}\text { Peso relativo ou comprimento do órgão } \\
\text { Organ relative weight or height }\end{array}$} \\
\hline & & $\begin{array}{c}1 \text { a } 7 \text { dias } \\
\text { From } 1 \text { to } 7 \text { days }\end{array}$ & $\begin{array}{c}1 \text { a } 21 \text { dias } \\
\text { From } 1 \text { to } 21 \text { days }\end{array}$ \\
\hline & & \multicolumn{2}{|c|}{$\begin{array}{l}\text { Comprimento do intestino }(\mathrm{cm}) \\
\text { Intestine height }(\mathrm{cm})\end{array}$} \\
\hline $\mathrm{EM}(\mathrm{kcal} / \mathrm{kg})$ & 2.850 & 80,33 & 111,83 \\
\hline$M E(\mathrm{kcal} / \mathrm{kg})$ & 3.000 & 82,08 & 111,33 \\
\hline Proteína $(\%)$ & 20 & 82,38 & 112,88 \\
\hline \multirow[t]{2}{*}{ Protein (\%) } & 23 & 78,63 & 110,25 \\
\hline & 26 & 82,63 & 113,25 \\
\hline \multirow[t]{2}{*}{$\mathrm{CV}^{2}(\%)$} & & 7,69 & 7,85 \\
\hline & & \multicolumn{2}{|c|}{$\begin{array}{l}\text { Peso relativo dos intestinos }(\%) \\
\text { Relative intestine weight }(\%)\end{array}$} \\
\hline $\mathrm{EM}(\mathrm{kcal} / \mathrm{kg})$ & 2.850 & 9,551 & 5,26 \\
\hline$M E(\mathrm{kcal} / \mathrm{kg})$ & 3.000 & 9,747 & 5,25 \\
\hline Proteína $(\%)$ & 20 & $8,620 \mathrm{~b}$ & $5,36 a b$ \\
\hline \multirow[t]{2}{*}{ Protein (\%) } & 23 & $9,914 \mathrm{a}$ & $5,52 \mathrm{a}$ \\
\hline & 26 & $10,413 a$ & $4,89 \mathrm{~b}$ \\
\hline \multirow[t]{2}{*}{$\mathrm{CV}^{2}(\%)$} & & 9,54 & 8,07 \\
\hline & & \multicolumn{2}{|c|}{ Peso relativo do fígado $(\%)$} \\
\hline $\mathrm{EM}(\mathrm{kcal} / \mathrm{kg})$ & 2.850 & 4,041 & 2,74 \\
\hline$M E(\mathrm{kcal} / \mathrm{kg})$ & 3.000 & 4,149 & 2,73 \\
\hline Proteína $(\%)$ & 20 & 4,094 & 2,66 \\
\hline \multirow[t]{2}{*}{ Protein (\%) } & 23 & 4,151 & 2,80 \\
\hline & 26 & 4,040 & 2,75 \\
\hline \multirow[t]{2}{*}{$\mathrm{CV}^{2}(\%)$} & & 11,49 & 7,84 \\
\hline & & \multicolumn{2}{|c|}{$\begin{array}{l}\text { Peso relativo do coração (\%) } \\
\text { Relative heart weight (\%) }\end{array}$} \\
\hline $\mathrm{EM}(\mathrm{kcal} / \mathrm{kg})$ & 2.850 & 7,149 & 0,77 \\
\hline$M E(\mathrm{kcal} / \mathrm{kg})$ & 3.000 & 7,481 & 0,73 \\
\hline Proteína (\%) & 20 & 7,031 & 0,73 \\
\hline \multirow[t]{2}{*}{ Protein (\%) } & 23 & 7,873 & 0,73 \\
\hline & 26 & 7,041 & 0,79 \\
\hline $\mathrm{CV}^{2}(\%)$ & & 14,31 & 15,07 \\
\hline
\end{tabular}

${ }^{1}$ Letras diferentes nas colunas indicam diferença estatística significativa (Tukey, $5 \%$ ).

${ }^{1}$ Minor letters in the rows indicates statistical difference (Tukey, 5\%).

$2 \mathrm{CV}=$ coeficiente de variação.

${ }^{2} \mathrm{CV}=$ coefficient of variation.

$26 \%$ PB) dentro do nível de $2.850 \mathrm{kcal} / \mathrm{kg}$ de EM também aponta para o nível de $23 \%$ de PB com os maiores pesos relativos dos intestinos (Tabela 8).

Para o percentual de peso da moela aos 21 dias de idade, o nível de $3.000 \mathrm{kcal} / \mathrm{kg}$ de EM mostrou maior peso do que o nível de $2.850 \mathrm{kcal} / \mathrm{kg}$ de EM para os tratamentos com $20 \%$ de PB. A interação entre os níveis de proteína dentro do nível de $3.000 \mathrm{kcal} / \mathrm{kg}$ de EM evidencia resultados semelhantes estatisticamente para os níveis de 20 e $23 \%$ de PB, e deste último com o de $26 \%$ de PB. O percentual de peso dos intestinos aos 21 dias de idade foi superior para os níveis de $23 \%$ de proteína bruta, diferindo estatisticamente dos tratamentos que continham 26\% de PB (Tabela 8). 
Tabela 8 - Interação dos pesos relativos (peso dos órgãos em relação ao peso corporal) da moela e do coração de frangos de corte aos 7 e 21 dias de idade, recebendo as rações experimentais

Table 8 - Statistical interaction for relative weight (organ weight related to body weight) of gizzard for broilers at 7 and 21 days of age fed experimental rations

\begin{tabular}{|c|c|c|c|}
\hline & \multicolumn{3}{|c|}{$\begin{array}{l}\text { Peso relativo da moela aos } 7 \text { dias de idade }(\%) \\
\quad \text { Relative gizzard weight at } 7 \text { days of age }(\%)\end{array}$} \\
\hline & 2.850 & 3.000 & Médias (Means) \\
\hline 20 & 6,755 & 7,308 & 7,031 \\
\hline 23 & 7,550 & 8,159 & 7,873 \\
\hline 26 & 7,143 & 6,940 & 7,041 \\
\hline \multirow[t]{3}{*}{ Médias (Means) } & 7,149 & 7,481 & $\mathrm{CV}^{*}=14,31 \%$ \\
\hline & \multicolumn{3}{|c|}{$\begin{array}{l}\text { Peso relativo da moela aos } 21 \text { dias de idade (\%) } \\
\text { Relative gizzard weight at } 21 \text { days of age (\%) }\end{array}$} \\
\hline & 2.850 & 3.000 & Médias (Means) \\
\hline 20 & $3,27 \mathrm{~A}$ & $4,20 \mathrm{aB}$ & 3,74 \\
\hline 23 & $3,48 \mathrm{~A}$ & $3,46 \mathrm{abA}$ & 3,47 \\
\hline 26 & $3,64 \mathrm{~A}$ & $3,00 \mathrm{bA}$ & 3,32 \\
\hline Médias (Means) & 3,46 & 3,55 & $\mathrm{CV}^{*}=13,37 \%$ \\
\hline
\end{tabular}

${ }^{1}$ Letras minúsculas diferentes nas colunas (proteína) ou maiúsculas nas linhas (energia) indicam diferença estatística significativa (Tukey, 5\%).

${ }^{1}$ Minor letters in the rows (protein) or major in lines (energy) indicates statistical difference (Tukey, 5\%).

${ }^{2} \mathrm{CV}=$ coeficiente de variação.

${ }^{2} \mathrm{CV}=$ coefficient of variation.

\section{Conclusões}

Nas condições experimentais, os níveis de proteína bruta mais altos (23 e $26 \%)$ na fase pré-inicial foram os que permitiram menor consumo de ração para frangos de corte na primeira semana e no período de 1 a 21 dias de idade e piora na digestibilidade da matéria seca na primeira semana. Entretanto, nenhum efeito dos níveis energéticos foi observado tanto para desempenho, como para os valores de digestibilidade de matéria seca e de nitrogênio obtidos.

\section{Literatura Citada}

BARANYIOVÁ, E.; HOLMAN, J. Morphological changes in the intestinal wall in fed and fasted chickens in the first week after hatching. Acta Veterinaria Brno, v.45, p.151-158, 1976 .

CROOM, W.J.; BRAKE, J.; COLES, B.A. et al. Is intestinal absorption capacity rate-limiting for performance in poultry. Journal of Applied Poultry Research, v.8, p.242-252, 1999.

DIBNER, J. Nutritional requirements of young poultry. In: MEETING OF ARKANSAS NUTRITION CONFERENCE, 1996, Fayetteville. Proceedings... Fayetteville: Arkansas Poultry Federation, 1996. p.15-27.

FREITAS, B.C.F.; BAIÃO, N.C.; NUNES, I.J. et al. Digestibilidad de la grasa en las primeras semanas de vida del pollo de carne. In: CONGRESSO LATINO-AMERICANO DE AVICULTURA, 16., Lima, 1999. Anais... Lima: APAVI, 1999. p.356-359.

GONZALES, E.; SALDANHA, E.S.P.B. Os primeiros dias de vida do frango e a produtividade futura. In: CONGRESSO BRASILEIRO DE ZOOTECNIA - ZOOTEC, 11., 2001,
Goiânia. Anais... Goiânia: UCG, 2001. p.310-327.

LIMA, I.L. Níveis nutricionais utilizados nas rações pela indústria avícola. In: SIMPÓSIO INTERNACIONAL SOBRE EXIGÊNCIAS NUTRICIONAIS DE AVES E SUÍNOS, Viçosa, 1996. Anais... Viçosa: Universidade Federal de Viçosa, 1996. p.389-401.

LU, J.; SHEN, T. Development of digestive organs and digestive enzymes for protein in broilers. In: ASIAN PACIFIC POULTRY CONGRESS, 6., Nagoya, 1998. Anais... Nagoya: Japan Poultry Science Association, 1998. p.344-345.

MAHAGNA, M.; NIR, I. Comparative development of digestive organs, intestinal disaccharidases and some blood metabolites in broiler and layer-type chicks after hatching. British Poultry Science, v.37, p.359-371, 1996.

MAIORKA, A.; LECZNIESKI, J.; BARTELS, H.A. et al. Efeito do nível energético da ração sobre o desempenho de frangos de corte de 1 a 7, 7 a 14 e 14 a 21 dias de idade. In: CONFERÊNCIA APINCO DE CIÊNCIA E TECNOLOGIA AVÍCOLAS - PRÊMIO LAMAS DE PESQUISA AVÍCOLA, 1997, Campinas. Trabalhos de Pesquisa... Campinas: Fundação APINCO de Ciência e Tecnologia Avícolas, 1997. p.18.

MORAN Jr., E. T. Digestion and absorption of carbohydrates in fowl and events through perinatal development. Journal of Nutrition, v.115, p.665-671, 1985.

NASCIMENTO, A.H.; ALBINO, L.F.T.; POZZA, P.C. et al. Energia e relação energia: proteína na fase inicial de frangos de corte. In: CONFERÊNCIA APINCO DE CIÊNCIA E TECNOLOGIA AVÍCOLAS - PRÊMIO LAMAS DE PESQUISA AVÍCOLA, Campinas, 1998. Trabalhos de Pesquisa... Campinas: Fundação APINCO de Ciência e Tecnologia Avícolas, 1998. p.15.

NITSAN, Z.; BEN-AVRAHAM, G.; ZOREF, Z. et al. Growth and development of the digestive organs and some enzymes in broiler chicks after hatching. British Poultry Science, v.32, p.515-523, 1991.

R. Bras. Zootec., v.32, n.1, p.162-170, 2003 
NOY, Y.; SKLAN, D. Digestion and absorption in the young chick. Poultry Science, v.74, p.366-373, 1995.

NOY, Y.; SKLAN, D. Post hatch development in poultry. Journal of Applied Poultry Research, v.6, p.344-354, 1997.

NOBRE, P.T.C.; BUTOLO, E.A.F.; SERAFINI, F.V. Influência dos níveis de taurina e energia metabolizável na performance de frangos de corte. In: CONFERÊNCIA APINCO DE CIÊNCIA E TECNOLOGIA AVÍCOLAS - PRÊMIO LAMAS DE PESQUISA AVÍCOLA, Campinas, 1998. TrabaIhos de Pesquisa... Campinas: Fundação APINCO de Ciência e Tecnologia Avícolas, 1998. p.39.

PENZ Jr., A.M.; VIEIRA, S.L. Nutrição na primeira semana. In: CONFERÊNCIA APINCO DE CIÊNCIA E TECNOLOGIA AVÍCOLAS, 1998, Campinas. Anais... Campinas: Fundação APINCO de Ciência e Tecnologia Avícolas, 1998. p.121-139.

ROSTAGNO, H.S.; SILVA, D.S.; COSTA, P.M.A. et al. Composição de alimentos e exigências nutricionais de aves e suínos (tabelas brasileiras). Viçosa, MG: Universidade Federal de Viçosa, 1994. 59p.
SILVA, D.J. Análise de alimentos (métodos químicos e biológicos). 2.ed. Viçosa, MG: Universidade Federal de Viçosa, 1990. $165 \mathrm{p}$.

STRINGHINI, J.H. Níveis de proteína e aminoácidos em rações para frangos de corte criados em duas densidades populacionais. Jaboticabal: Universidade Estadual Paulista, 1998. 123p. Tese (Doutorado em Zootecnia) - Universidade Estadual Paulista, 1998.

UNI, Z.; NOY, Y.; SKLAN, D. Development of the small intestine in heavy and light strain chicks before and after hatching. British Poultry Science, v.36, p.63-71, 1995a.

UNI, Z.; NOY, Y.; SKLAN, D. Post hatch changes in morphology and function of the small intestines in heavy- and lightstrain chicks. Poultry Science, v.74, p.1622-1629, 1995b.

UNI, Z.; GANOT, S.; SKLAN, D. Post hatch development of mucosal function in the broiler small intestine. Poultry Science, v.77, p.75-82, 1998.

Recebido em: 12/03/01

Aceito em: 21/05/02 